\title{
Zinc Chloride Catalyzed Regioselective Nitration of Aromatic Hydrocarbons Using Tetrachlorosilane-Sodium Nitrate Homogeneous System
}

\author{
Saad S. Elmorsy, Saad Shaaban*, Fathy Eldesoky, Ezzat Kandeel \\ Department of Chemistry, Faculty of Science, Mansoura University, Mansoura, Egypt \\ Email: ${ }^{\text {dr_saad chem@mans.edu.eg }}$
}

Received 5 April 2015; accepted 22 May 2015; published 25 May 2015

Copyright (C) 2015 by authors and Scientific Research Publishing Inc.

This work is licensed under the Creative Commons Attribution International License (CC BY). http://creativecommons.org/licenses/by/4.0/

(c) (;) Open Access

\begin{abstract}
The development of a new silane reagent derived from tetrachlorosilane (TCS) was applied in the present work. TCS-sodium nitrate $\left(\mathrm{NaNO}_{3}\right)$ binary reagent and zinc chloride $\left(\mathrm{ZnCl}_{2}\right)$ were reported here as a homogeneous nitrating system. The later was used for the efficient mono nitration, in most cases, with high para-regioselectivity. The nitration proceeded smoothly under mild condition, fairly clean and in good yields. This readily available and inexpensive system is superior to other methods by avoidance of the use of corrosive nitrating reagents and therefore considered to be convenient in terms of risk reduction, economic advantages and environment protection. The present protocol was convenient and applicable to a variety of aromatic hydrocarbons and could be amenable to high throughput synthesis of combinatorial libraries for potential drug development, which needs to be studied as part of future investigations.
\end{abstract}

\section{Keywords}

Nitration, Regioselectivity, Sodium Nitrate, Tetrachlorosilane

\section{Introduction}

Nitrated aryl compounds remained indispensable over the last two centuries due to their industrial and commercial applications [1]-[3]. They are used as plastics, agrochemicals, explosives, dyes, pigments and polymers [4]. These compounds can be synthesized from aryl precursors employing various nitrating reagents (e.g., nitric acid,

${ }^{*}$ Corresponding author.

How to cite this paper: Elmorsy, S.S., Shaaban, S., Eldesoky, F. and Kandeel, E. (2015) Zinc Chloride Catalyzed Regioselective Nitration of Aromatic Hydrocarbons Using Tetrachlorosilane-Sodium Nitrate Homogeneous System. International Journal of Organic Chemistry, 5, 49-56. http://dx.doi.org/10.4236/ijoc.2015.52006 
metallic nitrates, nitronium salts and acetyl nitrates) [5] [6]. In this context, aromatic nitration in homogeneous and heterogeneous media was the subject of many outstanding reviews and monographs [5]-[10].

In spite of the diverse investigations performed and the progression made to the nitration process, most of these strategies are facing several drawbacks. The general keys among them are the acidic corrosivity of the nitrating agents, poor regioselectivity and environmental pollution [11]-[15]. Furthermore, nitrations are usually associated with heat which in turn may cause secondary reactions or decomposition of the final product which consequently leads to low purity and yields [16]-[19]. Moreover, redox sensitive compounds and acid-hydrolysable groups are not eligible under these conditions [20]-[24].

Industrially speaking, nitrations under milder conditions received much attention in order to overcome obstacles associated with the hazards of the nitrating reagents. Advances in this field included palladium catalyzed nitration, the use of nitrate salts and catalyst-free nitration of aryl boronic acids [11] [20] [22] [25]-[29]. Although these methods were successful in limiting the use of corrosive and harsh reagents, these reagents were not cheap [30]-[36]. Furthermore, these agents were difficult to prepare, store and handle. Moreover, low degrees of chemoselectivity were often associated with certain aromatic systems. In this context, there are strong stimulants for the development of continuous fixed bed catalytic methods for the regioselective nitration of aromatic hydrocarbons.

\section{Material and Methods}

All chemical reagents for the synthesis of compounds were purchased from Sigma-Aldrich-Fluka or Merck (AMD) and used without further purification unless stated otherwise. Unless noted otherwise, silica gel 60 (Macherey-Nagel, 50 - $200 \mu \mathrm{m}$ ) was used for column chromatography. TLC plates (silica gel $60 \mathrm{~F}_{254}, 0.20 \mathrm{~mm}$ ) were purchased from Merck. All melting points were determined on a Gallenkamp electric melting point apparatus. IR spectra were recorded using $\mathrm{KBr}$ disks with a Mattson 5000 FTIR spectrometer, Faculty of Science, Cairo University. The ${ }^{1} \mathrm{H}$ NMR data were measured in $\mathrm{CDCl}_{3}$ or DMSO- $\mathrm{d}_{6}$ on a Varian XL 200, $300 \mathrm{MHz}$ instruments using TMS as an internal standard were carried out at the Micro Analytical Center of Cairo Univ., Giza, Egypt. Chemical shifts were reported in ppm $(\delta)$ downfield from that of TMS and coupling constants are expressed in hertz. Mass spectra were recorded on GC-MS QP-1000 EX. Shimadzu Instrument (Faculty of Science, Cairo University). These spectra indicated $\geq 99 \%$ MS-purity of the prepared compounds.

Typical experimental procedure for the nitration of phenol: to a stirred solution of the phenol $(94.11 \mathrm{mg}, 1$ mmol) in dichloromethane ( $10 \mathrm{~mL}$ ), $\mathrm{NaNO}_{3}(84.9 \mathrm{mg}, 1 \mathrm{mmol})$ was added. TCS (229.59 $\left.\mu \mathrm{l}, 2 \mathrm{mmol}\right)$ and $\mathrm{ZnCl}_{2}$ (13.63 $\mathrm{mg}, 10 \%$ mole) were then added and the reaction mixture was stirred at room temperature in the dark for the indicated period in Table 1. After completion of the reaction (monitored by TLC), water was added and the reaction mixture was extracted with dichloromethane $(25 \mathrm{~mL} \times 4)$ and dried over $\mathrm{Na}_{2} \mathrm{SO}_{4}$. The solvent was distilled off and the resulting crude product can be separated either by steam distillation or by silica gel (60 - 120 mesh) using petroleum ether-ethyl acetate mixture as eluent to give a pure compound.

\section{Nitrobenzene [37]:}

Yield $=90 \%$, yellow colored liquid, bp $210^{\circ} \mathrm{C}$. IR (liquid film): $v_{\max }=3108,3078,2935,1620,1607,1521$, 1382, 1363, 1347, 1317, $1308 \mathrm{~cm}^{-1} .{ }^{1} \mathrm{H}-\mathrm{NMR}\left(400 \mathrm{MHz}, \mathrm{CDCl}_{3}\right): \delta_{\mathrm{H}}=\delta 8.26-8.17(\mathrm{~m}, 2 \mathrm{H}), 7.42-7.35(\mathrm{~m}, 2 \mathrm{H})$, 7.47 (t, J = $7.47 \mathrm{~Hz}, 1 \mathrm{H}), 7.62-7.50$ (m, 2H).

1-Nitronaphthalene [38]:

Yield $=90 \%$, yellow colored solid, $\mathrm{mp} 50^{\circ} \mathrm{C}-52^{\circ} \mathrm{C}$. IR (KBr): $v_{\max }=2924,1519,1338,1260,804,763 \mathrm{~cm}^{-1}$. ${ }^{1} \mathrm{H}-\mathrm{NMR}\left(400 \mathrm{MHz}, \mathrm{CDCl}_{3}\right): \delta_{\mathrm{H}}=\delta 8.43(\mathrm{dd}, \mathrm{J}=0.96,8.64 \mathrm{~Hz}, 1 \mathrm{H}), 8.10(\mathrm{dd}, \mathrm{J}=1.21,7.62 \mathrm{~Hz}, 1 \mathrm{H}), 7.99(\mathrm{~d}, \mathrm{~J}$ $=8.21 \mathrm{~Hz}, 1 \mathrm{H}), 7.83(\mathrm{~d}, \mathrm{~J}=8.39 \mathrm{~Hz}, 1 \mathrm{H}),, 7.55-7.63(\mathrm{~m}, 1 \mathrm{H}), 7.46-7.54(\mathrm{~m}, 1 \mathrm{H}), 7.41(\mathrm{t}, \mathrm{J}=7.94 \mathrm{~Hz}, 1 \mathrm{H})$.

4-Nitrotoluene [39]:

Yield $=65 \%$, yellow colored solid, $\mathrm{mp} 50^{\circ} \mathrm{C}-52^{\circ} \mathrm{C}$. IR $(\mathrm{KBr}): v_{\max }=3109,3084,2939,2834,1604,1598$, 1567, 1512, 1495, 1469, 1379, 1366, 1353, 1346, 1322, 1297, 1180, 1116, 1108, 1018, 859, 839, 786, 738, 633, $619 \mathrm{~cm}^{-1} .{ }^{1} \mathrm{H}-\mathrm{NMR}\left(400 \mathrm{MHz}, \mathrm{CDCl}_{3}\right): \delta_{\mathrm{H}}=8.14(\mathrm{~d}, 2 \mathrm{H}), 7.49(\mathrm{~d}, 2 \mathrm{H}), 2.34(\mathrm{~s}, 3 \mathrm{H})$.

4-Nitrophenol [37]:

Yield $=55 \%$, yellow colored solid, $\mathrm{mp} 108^{\circ} \mathrm{C}-110^{\circ} \mathrm{C} . \mathrm{IR}(\mathrm{KBr}): v_{\max }=3360,3119,3078,2921,1613,1593$, 1496, 1337, 1295, 1113,864 $\mathrm{cm}^{-1} .{ }^{1} \mathrm{H}-\mathrm{NMR}\left(400 \mathrm{MHz}, \mathrm{CDCl}_{3}\right): \delta_{\mathrm{H}}=9.83(\mathrm{~s}, 1 \mathrm{H}), 8.09(\mathrm{~d}, 2 \mathrm{H}), 7.08(\mathrm{~d}, 2 \mathrm{H})$.

2-Nitrophenol [37]:

Yield $=35 \%$, yellow colored solid, $\mathrm{mp} 44^{\circ} \mathrm{C} . \mathrm{IR}(\mathrm{KBr}): v_{\max }=3240,3113,3091,2924,1617,1589,1534$, 
Table 1. Effect of solvents in the nitration of phenol with $\mathrm{NaNO}_{3} / \mathrm{TCS}$.

\begin{tabular}{|c|c|c|c|c|c|}
\hline entry & Solvent & $\begin{array}{l}\text { Conversion time } \\
\text { (min) }\end{array}$ & $\begin{array}{l}\text { Substrates molar ratios } \\
\text { Phenol: } \mathrm{NaNO}_{3}: \mathrm{SiCl}_{4}{ }^{\mathrm{a}}\end{array}$ & Product(s) & Yield\% \\
\hline 1 & Ethanol & 0 & $1: 1: 1$ & $\mathrm{~b}$ & - \\
\hline 2 & Ethanol & 0 & $1: 2: 2$ & $\mathrm{~b}$ & - \\
\hline 3 & Diethyl ether & 0 & $1: 1: 1$ & c & - \\
\hline 4 & Diethyl ether & 0 & $1: 2: 2$ & c & - \\
\hline 5 & Tetrahydrofuran & 0 & $1: 1: 1$ & c & - \\
\hline 6 & Tetrahydrofuran & 0 & $1: 2: 2$ & c & - \\
\hline 7 & Chloroform & 260 & $1: 2: 2$ & $\begin{array}{l}\text { o-nitrophenol } \\
\text { p-nitrophenol }\end{array}$ & $\begin{array}{l}35 \\
55\end{array}$ \\
\hline 8 & Dichloromethane & 30 & $1: 1: 1$ & $\begin{array}{l}o \text {-nitrophenol } \\
p \text {-nitrophenol }\end{array}$ & $\begin{array}{l}40 \\
60\end{array}$ \\
\hline 9 & Dichloromethane & 30 & $1: 2: 1$ & $\begin{array}{l}o \text {-nitrophenol } \\
\text { p-nitrophenol }\end{array}$ & $\begin{array}{l}40 \\
60\end{array}$ \\
\hline 10 & Dichloromethane & 30 & 1:1:1.5 & $\begin{array}{l}\text { o-nitrophenol } \\
\text { p-nitrophenol }\end{array}$ & $\begin{array}{l}30 \\
70\end{array}$ \\
\hline 11 & Dichloromethane & 30 & $1: 1: 2$ & $\begin{array}{l}\text { o-nitrophenol } \\
\text { p-nitrophenol }\end{array}$ & $\begin{array}{l}10 \\
90\end{array}$ \\
\hline
\end{tabular}

a. No reaction was observed in the absence of TCS; b. The reaction was exothermic, low yielding and the formation of unresolved by-products was constantly observed; c. No reaction.

1478, 1449, 1372, 1332, 1315, 1177, 1078, $1026 \mathrm{~cm}^{-1} .{ }^{1} \mathrm{H}-\mathrm{NMR}\left(400 \mathrm{MHz}, \mathrm{CDCl}_{3}\right): \delta_{\mathrm{H}}=10.57(\mathrm{~s}, 1 \mathrm{H}), 8.10$ (dd, J = 8.4, 1.7 Hz, 1 H), 7.57 (dt, J = 8.5, 8.5, 1.7 Hz, 1H), 7.16 (ddd, J = 8.5, 1.5, 0.4 Hz, 1H), 6.88 (dt, J = 8.5, 8.4, $1.5 \mathrm{~Hz}, 1 \mathrm{H})$.

\section{2-Methyl-4-nitrophenol [37]:}

Yield $=90 \%$, yellow colored solid, $\mathrm{mp} 98^{\circ} \mathrm{C}-100^{\circ} \mathrm{C}$. IR $(\mathrm{KBr}): v_{\max }=3440,3214,3087,2928,1609,1541$, 1462, 1405, 1334, 1313, 1244, 1157, $679 \mathrm{~cm}^{-1} .{ }^{1} \mathrm{H}-\mathrm{NMR}\left(400 \mathrm{MHz}, \mathrm{CDCl}_{3}\right): \delta_{\mathrm{H}}=7.95$ (dd, J = 9.1, $4.4 \mathrm{~Hz}$, 1H), 7.90 (s, 1H), 7.09 (dd, J = 9.2, 4.7 Hz, 1H), 5.50 (s, 1H), 2.15 (s, 3H).

3-Methyl-4-nitrophenol [37]:

Yield $=90 \%$, yellow colored solid, $\mathrm{mp} 112^{\circ} \mathrm{C}-118^{\circ} \mathrm{C} . \mathrm{IR}(\mathrm{KBr}): v_{\max }=3282,3103,3049,2927,1624,1572$, 1527, 1469, 1448, 1422, 1384, 1309, 1259, 1175, 1156, 1102, $851 \mathrm{~cm}^{-1} .{ }^{1} \mathrm{H}-\mathrm{NMR}\left(400 \mathrm{MHz}, \mathrm{CDCl}_{3}\right): \delta_{\mathrm{H}}=8.05$ (m, $1 \mathrm{H}), 6.75$ (m, 2H), 5.51 (s, 1H), 2.34 (s, 3H).

4-Nitroresorcinol [40]:

Yield $=60 \%$, yellow solid, $\mathrm{mp} 80^{\circ} \mathrm{C}-82^{\circ} \mathrm{C}$. IR $(\mathrm{KBr}): v_{\max }=3354,1532,1397,1255 \mathrm{~cm}^{-1} .{ }^{1} \mathrm{H}-\mathrm{NMR}(400$ $\mathrm{MHz}, \mathrm{CDCl}_{3}$ ): $\delta_{\mathrm{H}}=10.97(\mathrm{~s}, 2 \mathrm{H}), 7.45$ (d, J = 9.2 Hz, 1H), 6.52 (d, J = 3.4 Hz, 1H), 6.47 (dd, J = 9.2, 4.7 Hz, 1H).

2,4-Dinitroanisol [40]:

Yield $=45 \%$, yellowish powder, $\mathrm{mp} 94^{\circ} \mathrm{C}-95^{\circ} \mathrm{C}$. IR $(\mathrm{KBr}): v_{\max }=3091,1624,1607,1491,1466,1460,1438$, 1418, 1344, 1318, 1285, 1184, 1163, 1138, $1073 \mathrm{~cm}^{-1} .{ }^{1} \mathrm{H}-\mathrm{NMR}\left(400 \mathrm{MHz}, \mathrm{CDCl}_{3}\right): \delta_{\mathrm{H}}=8.703(\mathrm{~s}, 1 \mathrm{H}), 8.4(\mathrm{dd}$, $\mathrm{J}=8.4,4.8 \mathrm{~Hz}, 1 \mathrm{H}), 7.25$ (dd, J = 4.7, $1.5 \mathrm{~Hz}, 1 \mathrm{H}), 4.18$ (s, 3H).

\section{2,4-Dinitrophenol [41]:}

Yield $=90 \%$, yellow crystalline powder, mp $112^{\circ} \mathrm{C}-114^{\circ} \mathrm{C} . \mathrm{IR}(\mathrm{KBr}): v_{\max }=3272,3111,1627,1602,1595$, 1558, 1481, 1434, 1349, 1334, 1267, 1236, 1167, 1149, 1138, 1111, $1068 \mathrm{~cm}^{-1} .{ }^{1} \mathrm{H}-\mathrm{NMR}\left(400 \mathrm{MHz} \mathrm{CDCl}_{3}\right): \delta_{\mathrm{H}}$ $=11.03(\mathrm{~s}, 1 \mathrm{H}), 9.08$ (d, J = 2.8 Hz, 1H), 8.46 (dd, J = 8.5, $4.9 \mathrm{~Hz}, 1 \mathrm{H}), 7.34$ (d, J = 9.2 Hz, 1H).

1-Chloro-4-nitrobenzene [42]:

Yield $=70 \%$, Yellow crystals, $\operatorname{mp} 82^{\circ} \mathrm{C}-83^{\circ} \mathrm{C} . \mathrm{IR}(\mathrm{KBr}): v_{\max }=3106,3069,1604,1578,1519,1477,1424$, 
1403, 1383, 1358, 1344, 1314, 1238, 1175, 1109, 1095, $1013 \mathrm{~cm}^{-1} .{ }^{1} \mathrm{H}-\mathrm{NMR}\left(400 \mathrm{MHz}, \mathrm{CDCl}_{3}\right): 8.10$ (d, J = 2.5 $\mathrm{Hz}, 2 \mathrm{H}), 7.52$ (d, J = 2.4 Hz, 2H).

3-Nitroacetophenone [43]:

Yield $=45 \%$, white to light beige crystalline powder, $\mathrm{mp} 72^{\circ} \mathrm{C}-76^{\circ} \mathrm{C}$. IR $(\mathrm{KBr}): v_{\max }=2955,2923,2852$, 1693, 1633, 1462, 1378, 1279, $1209 \mathrm{~cm}^{-1} .{ }^{1} \mathrm{H}-\mathrm{NMR}\left(400 \mathrm{MHz}, \mathrm{CDCl}_{3}\right): \delta_{\mathrm{H}}=8.61$ (s, 1H), 8.45 (dd, J = 4.8, 1.5 $\mathrm{Hz}, 1 \mathrm{H}), 8.33$ (dd, J = 4.8, $1.5 \mathrm{~Hz}, 1 \mathrm{H}), 7.82(\mathrm{~m}, 1 \mathrm{H}), 2.50$ (s, $3 \mathrm{H})$.

3-Nitropyridine [44]:

Yield $=80 \%$, white to light beige crystalline liquid, mp 41 - 42 (lit. 120; 40 Torr) ${ }^{\circ} \mathrm{C}$. IR (KBr): $v_{\max }=3058$, 2868, 1602, 1571, 1526, 1471, 1427, 1353, $1239 \mathrm{~cm}^{-1} .{ }^{1} \mathrm{H}-\mathrm{NMR}\left(400 \mathrm{MHz}, \mathrm{CDCl}_{3}\right): \delta_{\mathrm{H}}=7.60$ (dd, J = 8.4, 4.8 Hz, 1H), 8.53 (ddd, J = 8.4, 2.6, 1.5 Hz, 1H), 8.96 (dd, J = 4.8, 1.5 Hz, 1H), 9.46 (d, J = 2.6 Hz, 1H).

\section{Results and Discussion}

In continuation of our previous studies on the application of TCS in organic synthesis [45]-[47] herein we report a simple, mild and convenient regioselective nitration of different aromatic hydrocarbons using TCS and inorganic nitrate salt (Figure 1).

This combination was not reported earlier in the literature and we are currently exploring the potential using of this reagent system in further organic transformations. Our main objective was to overcome the nitration's associated drawbacks such as acidic corrosivity, tedious work up and safety problems (preparation, storage and handling of the nitrating agent). Furthermore, the use of one-pot synthesis has attracted our interest since it is easily performed and usually offers high yield.

In order to find out suitable reaction conditions, the reaction of phenol with TCS and $\mathrm{NaNO}_{3}$ was preliminary examined in different solvents and at different molar ratios. The use of ethanol leads to exothermic reaction, low yielding and the formation of by-products. Oxygenated donor solvents (e.g., tetrahydrofuran, diethyl ethers) were also non convenient as they completely inhibited the reaction (Table 1).

The use of chloroform and dichloromethane led to minimization of the side products; however, reaction in dichloromethane affords better yield than in chloroform. We therefore decided to perform the reaction in dichloromethane and optimize the other reaction conditions. The reaction was then carried out using different molar ratios of TCS, $\mathrm{NaNO}_{3}$ with respect to phenol in dichloromethane. It is worth noting that, no reaction was observed in the absence of TCS. Furthermore, the use of equimolar amounts of reagent $\left(\mathrm{TCS}-\mathrm{NaNO}_{3}\right)$ and substrate led to large quantities recovery of the staring materials. $\mathrm{NaNO}_{3}$ concentration was therefore increased in order to improve the yield. This was found to be ineffective neither on the reaction productivity nor to the reaction selectivity (monitored by TLC). Interestingly, yields improvement and by-products minimization were observed via increasing the concentration of the TCS (monitored by TLC). After a long term of trials, good yields were obtained when the TCS molar ratio was twice the aromatic hydrocarbon and the nitrate salt i.e. aromatic substrate: nitrate salt: TCS molar ratio was 1:1:2, respectively (Table 1). Further increment of the molar ratio of TCS led to the formation of a mixture of di- and tri-nitro derivatives. The reaction was performed under the dark and at room temperature.

The typical reaction accomplishment time was up to 6 hours (monitored by TLC). This led us to consider the addition of catalyst (e.g., Lewis acids) in order to reduce the reaction time. The addition of $\mathrm{ZnCl}_{2}(10 \mathrm{~mol} \%)$ is associated with rate enhancement and reduction of the reaction time (up to $2 \mathrm{~h}$ ) (see experimental part for more details).

A reasonable mechanism for the present reaction might proceed as depicted in Figure 2. It was assumed that $\left(\mathrm{O}_{2} \mathrm{NO}\right) \mathrm{SiCl}_{3}$ intermediate was generated and its further reacted with excess TCS to form nitryl chloride $\left(\mathrm{NO}_{2} \mathrm{Cl}\right)$.

It is though that the in situ formed $\mathrm{NO}_{2} \mathrm{Cl}$ is further activated via coordination with $\mathrm{ZnCl}_{2}$ to give the corres-

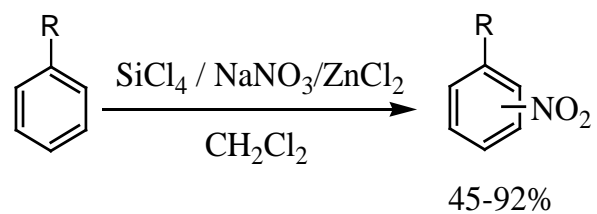

Figure 1. Nitration of aromatic hydrocarbons using tetrachlorosilane-sodium nitrate homogeneous system. 
ponding nitronium salt $\mathrm{NO}_{2}^{+} \mathrm{ZnCl}_{3}^{-}$which in turn is considered to be a very reactive nitrating agent (even more powerful than the dinitrogen pentoxide) (Figure 3). The later acted as the nitronium source and ultimately reacted with aromatic hydrocarbons to give the corresponding mononitro derivatives.

This pilot reaction endured a considerable diversity of functionalized aromatics (e.g., benzene, naphthalene and alkyl, alkoxy, hydroxy and acetyl substituted-benzene) (Table 2). The nitration of benzene, naphthalene, phenol, 2-methylphenol and 3-methylphenol offered high yield (60\% - 92\%). On the other hand, acetophenone were nitrated in low yield (40\%).

The para isomer was isolated in most cases. The reason was mainly attributed to steric hindrance between the substituents and the electrophilic group, especially in the ortho-position. On the other hand, no reaction was observed in case of benzoic acid, aniline and benzaldehyde. Groups that withdraw electron density (e.g. $\mathrm{COOH}$ and $\mathrm{CHO}$ ) causes strong deactivation. This may be the reason that no nitration reaction was observed in case of benzoic acid and benzaldehyde.

Despite the fact that the $\mathrm{NH}_{2}$ group is a much more powerful activating group than $\mathrm{COOH}$ and $\mathrm{CHO}$, aniline also failed to react under these conditions and a black tar is formed. This may be attributed to the side reaction

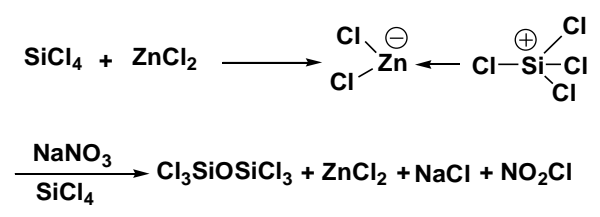

Figure 2. Formation of nitryl chloride, the source of nitronium salt $\mathrm{NO}_{2}^{+}$.

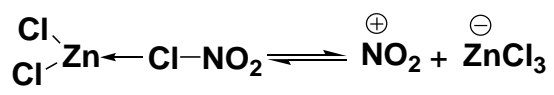

Figure 3. Activation of nitryl chloride by coordination with zinc chloride.

Table 2. Nitration of various aromatic hydrocarbons to their corresponding mono nitro derivative employing $\mathrm{SiCl}_{4} / \mathrm{ZnCl}_{2} /$ $\mathrm{NaNO}_{3}$ combination in dichloromethane.

\begin{tabular}{|c|c|c|c|c|c|c|}
\hline Entry & Substrate & Product(s) ${ }^{\mathrm{a}}$ & Time (min) & Temp. $\left({ }^{\circ} \mathrm{C}\right)$ & Yield\% & Melting/boiling point $\left({ }^{\circ} \mathrm{C}\right)$ \\
\hline 1 & Benzene & Nitrobenzene & 120 & 25 & $65 \%$ & $209-210$ \\
\hline 2 & Naphthalene & 1-Nitronaphthalene & 50 & 25 & $92 \%$ & $53-57$ \\
\hline 3 & Toluene & 4-Nitrotoluene & 120 & 25 & $90 \%$ & $52-54$ \\
\hline 4 & Phenol & $\begin{array}{l}\text { 2-Nitrophenol } \\
\text { 4-Nitrophenol }\end{array}$ & 30 & 0 & $\begin{array}{l}35 \% \\
55 \%\end{array}$ & $\begin{array}{c}43-47 \\
110-115\end{array}$ \\
\hline 5 & 2-Methylphenol & 2-Methyl-4-nitrophenol & 50 & 0 & $90 \%$ & 96 \\
\hline 6 & 3-Methylphenol & 3-Methyl-4-nitrophenol & 50 & 0 & $90 \%$ & $125-130$ \\
\hline 7 & 4-Methylphenol & 4-Methyl-2-nitrophenol & 50 & 0 & $90 \%$ & $32-35$ \\
\hline 8 & 2-Nitrophenol & 2,4-Dinitrophenol & 60 & 25 & $90 \%$ & 108 \\
\hline 9 & Resorcinol & 4-Nitroresorcinol & 30 & 25 & $60 \%$ & $81-83$ \\
\hline 10 & Anisole & 2,4-Dinitroanisole & 120 & 25 & $45 \%$ & $94-96$ \\
\hline 11 & Chlorobenzene & 1-Chloro-4-nitrobenzene & 80 & 25 & $70 \%$ & $80-83$ \\
\hline 12 & Acetophenone & 3-Nitroacetophenone & 120 & 25 & $40 \%$ & 78 \\
\hline 13 & Pyridine & 3-Nitropyridine & 300 & 25 & $80 \%$ & 40 \\
\hline
\end{tabular}

a. All the reactions were performed using $1 \mathrm{mmol}$ of substrate, $1 \mathrm{mmol}$ of $\mathrm{NaNO}_{3}, 2 \mathrm{mmol}$ of $\mathrm{TCS}$ and catalytic amount of $\mathrm{ZnCl} 2(10 \%$ mmol). 
which might take place between the TCS and the $\mathrm{NH}_{2}$ group (e.g., oxidation). Currently, this reaction is being expanded in our lab employing different conditions (solvents and catalysts) and with wider variety of substrates. On the other hand, the strongly activating, electron donating, - $\mathrm{OH}$ group(s) favour aromatic nitration via the activation of the ortho-para centers. In this case, the highest electron density is located on both ortho and para positions due to resonance donating effect of the hydroxyl group.

\section{Conclusion}

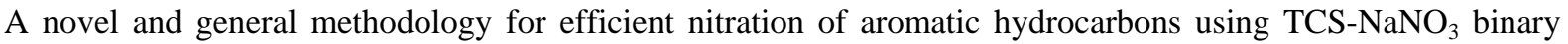
reagent and $\mathrm{ZnCl}_{2}$ was reported. This method is easy to perform and provides moderate-high yields. In order to establish the complete picture about the durability and efficiency of this method, some points are needed to be further clarified. This includes the evidence that $\mathrm{ZnCl}_{2}$ provides a positive effect not only on the activation of $\mathrm{NO}_{2} \mathrm{Cl}$ but also on the other steps (see the mechanism). Moreover, more data with further experiments such as

${ }^{29} \mathrm{Si}$ NMR study and MS analysis using considerably wider functionalities of aromatic, aliphatic and heterocyclic hydrocarbons need to be further investigated. We see a plenty of room for further, multi-disciplinary studies involving synthetic and mechanistic studies in order to develop convenient nitration method by applying TCS.

\section{Acknowledgements}

The authors wish to express their sincere thanks to staff members of Organic Chemistry Research Labs. at Chemistry Department, Faculty of Science, Mansoura University, Egypt for the facilities and support provided.

\section{References}

[1] Kilpatrick, B., Heller, M. and Arns, S. (2013) Chemoselective Nitration of Aromatic Sulfonamides with Tert-Butyl Nitrite. Chemical Communications (Cambridge), 49, 514-516. http://dx.doi.org/10.1039/C2CC37481A

[2] Hajipour, A.R. and Ruohob, A.E. (2005) Nitric Acid in the Presence of $\mathrm{P}_{2} \mathrm{O}_{5}$ Supported on Silica Gel—A Useful Reagent for Nitration of Aromatic Compounds under Solvent-Free Conditions. Tetrahedron Letters, 46, 8307-8310. http://dx.doi.org/10.1016/j.tetlet.2005.09.178

[3] Antes, J., Boskovic, D., Krause, H., Loebbecke, S., Lutz, N., Tuercke, T. and Schweikert, W. (2003) Analysis and Improvement of Strong Exothermic Nitrations in Microreactors. Chemical Engineering Research and Design, 81, 760765. http://dx.doi.org/10.1205/026387603322302931

[4] Yan, G. and Yang, M. (2013) Recent Advances in the Synthesis of Aromatic Nitro Compounds. Organic Biomolecular Chemistry, 11, 2554-2566. http://dx.doi.org/10.1039/c3ob27354g

[5] Ono, N. (2001) The Nitro Group in Organic Synthesis. Wiley, Hoboken. http://dx.doi.org/10.1002/0471224480

[6] Olah, A.G., Malhotra, R. and Narang, C.S. (1989) Nitration. Methods and Mechanisms. VCH, New York, Weinheim.

[7] Hoggett, J.G, Moodie, R.B., Penton, J.R. and Schofield, K. (1971) Nitration and Aromatic Reactivity. Cambridge University Press, Cambridge.

[8] Esakkidurai, T. and Pitchumani, K. (2002) Zeolite-Mediated Regioselective Nitration of Phenol in Solid State. Journal of Molecular Catalysis A: Chemical, 185, 305-309. http://dx.doi.org/10.1016/S1381-1169(02)00135-8

[9] Iranpoora, N., Firouzabadia, Habib., Nowrouzia, N. and Firouzabadib, D. (2006) Highly Chemoselective Nitration of Aromatic Amines Using the $\mathrm{Ph}_{3} \mathrm{P} / \mathrm{Br}_{2} / \mathrm{AgNO}_{3}$ System. Tetrahedron Letters, 47, 6879-6881. http://dx.doi.org/10.1016/j.tetlet.2006.07.054

[10] Shokrolahi, A., Zali, A. and Keshavarz, M.H. (2007) Wet Carbon-Based Solid Acid/NaNO $\mathrm{Na}_{3}$ as Mild and Efficient Reagent for Nitration of Aromatic Compound under Solvent Free Conditions. Chinese Chemical Letters, 18, 10641066. http://dx.doi.org/10.1016/j.cclet.2007.06.031

[11] Peng, X.H., Suzuki, H. and Lu, C.X. (2001) Zeolite-Assisted Nitration of Neat Toluene and Chlorobenzene with a Nitrogen Dioxide/Molecular Oxygen System. Remarkable Enhancement of Para-Selectivity. Tetrahedron Letters, 42, 4357-4359. http://dx.doi.org/10.1016/S0040-4039(01)00750-X

[12] Bak, R.R. and Smallridge, J.A. (2001) A Fast and Mild Method for the Nitration of Aromatic Rings. Tetrahedron Letters, 42, 6767-6769. http://dx.doi.org/10.1016/S0040-4039(01)01378-8

[13] Iranpoor, N., Firouzabadi, H. and Heydari, R. (1999) Ionic Complex of $\mathrm{N}_{2} \mathrm{O}_{4}$ with 18-Crown-6: A Highly Efficient and Selective Reagent for Nitration of Phenols. Synthetic Communications, 29, 3295-3302. http://dx.doi.org/10.1080/00397919908085957

[14] Olah, A.G. and Kuhn, S.J. (1962) Aromatic Substitution XII. Steric Effects in Nitronium Salt Nitrations of Alkylben- 
zenes and Halobenzenes. Journal of the American Chemical Society, 84, 3684-3687.

[15] Nowrouzi, N. and Jonaghani, M.Z. (2011) Nitration of Aromatic Compounds under Neutral Conditions Using the $\mathrm{Ph}_{2} \mathrm{PCl} / \mathrm{I}_{2} / \mathrm{AgNO}_{3}$ Reagent System. Tetrahedron Letters, 52, 5081-5082. http://dx.doi.org/10.1016/j.tetlet.2011.07.097

[16] Ramana, M.M.V., Malik, S.S. and Parihar, J.A. (2004) Guanidinium Nitrate: A Novel Reagent for Aryl Nitrations. Tetrahedron Letters, 45, 8681-8683. http://dx.doi.org/10.1016/j.tetlet.2004.09.140

[17] Strazzolini, P., Giumanini, A.G. and Runcio, A. (2001) Nitric Acid in Dichloromethane Solution. Facile Preparation From Potassium Nitrate and Sulfuric Acid. Tetrahedron Letters, 42, 1387-1389. http://dx.doi.org/10.1016/S0040-4039(00)02253-X

[18] Bozell, J.J. and Hoberg, J.O. (1988) Catalytic Oxidation of Para-Substituted Phenols with Nitrogen Dioxide And Oxygen. Tetrahedron Letters, 39, 2261-2264. http://dx.doi.org/10.1016/S0040-4039(98)00242-1

[19] Iranpoor, N., Firouzabadia, H. and AliZolfigol, M. (1998) Efficient and Selective Mono and Dinitration of Phenols with $\mathrm{Cr}\left(\mathrm{NO}_{3}\right)_{3} \cdot 2 \mathrm{~N}_{2} \mathrm{O}_{4}$ as a New Nitrating Agent. Synthetic Communications, 28, 2773-2781. http://dx.doi.org/10.1080/00397919808004851

[20] Bahulayan, D., Narayan, G., Sreekumar, V. and Lalithambika, M. (2002) Natural Bentonite $\mathrm{Clay} / \mathrm{Dilute} \mathrm{HNO}_{3}$ (40\%)—A Mild, Efficient, and Reusable Ctatlyst/Reagent System for Selective Mono Nitration and Benzylic Oxidations. Synthetic Communications, 32, 3565-3574. http://dx.doi.org/10.1081/SCC-120014967

[21] Mellor, J.M., Mittoo, R.S. and Millar, R.W. (2000) Improved Nitrations Using Metal Nitrate-Sulfuric Acid Systems. Tetrahedron, 56, 8019-8024. http://dx.doi.org/10.1016/S0040-4020(00)00720-1

[22] Cornelis, A. and Laszlo, P. (1985) Clay-Supported Copper(II) and Iron(III) Nitrates: Novel Multi-Purpose Reagents for Organic Synthesis. Synthesis, 1985, 909-918. http://dx.doi.org/10.1055/s-1985-31382

[23] Olah, G.A., Krishnamurthy, V.V. and Narang, S.C. (1982) Aromatic Substitution. 50. Mercury(II)-Promoted Azeotropic nitration of Aromatics over Nafion-H Solid Superacidic Catalyst. Journal of Organic Chemistry, 47, 596-598. http://dx.doi.org/10.1021/jo00342a052

[24] Iranpoor, N., Firouzabadia, H., Heydaria, R. and Shiria, M. (2005) Nitration of Aromatic Compounds by $\mathrm{Zn}_{(}\left(\mathrm{NO}_{3}\right)_{2} \cdot 2 \mathrm{~N}_{2} \mathrm{O}_{4}$ and Its Charcoal-Supported System. Synthetic Communications, 35, 263-270. http://dx.doi.org/10.1081/SCC-200048450

[25] Samajdar, S., Becker, F.F. and Banik, K.B. (2000) Surface-Mediated Highly Efficient Regioselective Nitration of Aromatic Compounds by Bismuth Nitrate. Tetrahedron Letters, 41, 8017-8020. http://dx.doi.org/10.1016/S0040-4039(00)01397-6

[26] Parac-Vogt, T.N. and Binnemans, K. (2004) Lanthanide(III) Nosylates as New Nitration Catalysts. Tetrahedron Letters, 45, 3137-3139. http://dx.doi.org/10.1016/j.tetlet.2004.02.084

[27] Zolfigol, A.M., Ghasemi, E. and Madrakian, E. (2003) Trichloroisocyanuric Acid/ $\mathrm{NaNO}_{2}$ as a Novel Heterogeneous System for the Selective Mononitration of Phenols under Mild Conditions. Synlett, 2, 191-194. http://dx.doi.org/10.1055/s-2003-36791

[28] Frost, C.G., Hartley, J.P. and Griffin, D. (2002) Counterion Effects in Indium-Catalysed Aromatic Electrophilic Substitution Reactions. Tetrahedron Letters, 43, 4789-4791. http://dx.doi.org/10.1016/S0040-4039(02)00931-0

[29] Jacoway, J., Narayana Kumar, G.G.K.S. and Laali, K.K. (2012) Aromatic Nitration with Bismuth Nitrate in Ionic Liquids and in Molecular Solvents: A Comparative Study of $\mathrm{Bi}\left(\mathrm{NO}_{3}\right)_{3} \cdot 5 \mathrm{H}_{2} \mathrm{O} /[\mathrm{bmim}]\left[\mathrm{PF}_{6}\right]$ and $\mathrm{Bi}\left(\mathrm{NO}_{3}\right)_{3} \cdot 5 \mathrm{H}_{2} \mathrm{O} / 1,2-\mathrm{DCE}$ Systems. Tetrahedron Letters, 53, 6782-6785. http://dx.doi.org/10.1016/j.tetlet.2012.09.137

[30] Rajagopal, R. and Srinivasan, K.V. (2003) Ultrasound Promoted Para-Selective Nitration of Phenols in Ionic Liquid. Ultrasonics Sonochemistry, 10, 41-43. http://dx.doi.org/10.1016/S1350-4177(02)00099-8

[31] Loebbecke, S., Boskovic, D., Antes, J., Tuercke, T., Schweikert, W., Marioth, E., Schnuerer, F. and Krause, H. (2002) Application of Microreactors for the Synthesis of Energetic Materials. Process Improvements and Diagnostics. Proceedings of 33rd International Annual Conference ICT: Energetic Materials Synthesis, Production and Application, Karlsruhe, 25-28 June 2002, 42.

[32] Zolfigol, M.A., Madrakian, E. and Ghasemi, E. (2002) Silica Sulfuric Acid/NaNO 2 as a Novel Heterogeneous System for the Nitration of Phenols under Mild Conditions. Molecules, 7, 734-742. http://dx.doi.org/10.3390/71000734

[33] Dummann, G., Quittmann, U., Groeschel, L., Agar, D.W., Woerz, O. and Morgenschweis, K. (2002) Nitration of Single Ring Aromatics in a Capillary-Microreactor. Proceedings of 1st International Congress on the Process Industries, AchemAmerica, Mexico City.

[34] Olah, A.G., Reddy, V. and Prakash, S. (1992) Aromatic Nitration with Nitric Acid/Trifluoromethanesulfonic Anhydride. Synthesis, 11, 1087-1089. http://dx.doi.org/10.1055/s-1992-26310

[35] Laali, K.K. and Gettwert, V.J. (2001) Electrophilic Nitration of Aromatics in Ionic Liquid Solvents. Journal of Organic Chemistry, 66, 35-40. http://dx.doi.org/10.1021/jo000523p 
[36] Nowrouzi, N., Mehranpour, A.M., Bashiri, E. and Shayan Z. (2012) Aromatic Nitration under Neutral Conditions Using N-Bromosuccinimide/Silver(I) Nitrate. Tetrahedron Letters, 53, 4841-4842. http://dx.doi.org/10.1016/j.tetlet.2012.06.126

[37] Chuchev, K., Tadjer, A., Nikolova, N. and Nenov, V. (2005) Relationship between Molecular Characteristics and Biodegradation Rate of Benzene Derivates. Oxidation Communications, 28, 837-846.

[38] Datta, J. (1952) Reactions with Dry Alkaline Earth Hydroxides. 2. Reduction of Alpha Nitro Naphthalene and Dinitronaphthalene. Journal of the Indian Chemical Society, 29, 394-396.

[39] Taha, N., Sasson, Y. and Chidambaram, M. (2008) Phase Transfer Methodology for the Synthesis of Substituted Stilbenes under Knoevenagel Condensation Condition. Applied Catalysis A: General, 350, 217-224. http://dx.doi.org/10.1016/j.apcata.2008.08.011

[40] Shi, M. and Cui, S.C. (2003) Electrophilic Aromatic Nitration Using a Mixed Catalyst of Lithium, Molybdenum, Ytterbium on Silica Gel. Advanced Synthesis \& Catalysis, 345, 1197-1202. http://dx.doi.org/10.1002/adsc.200303111

[41] Preiss, A. (2005) Analysis of Highly Polar Compounds in Groundwater Samples from Ammunition Waste Sites. Part I-Characterization of the Pollutant Spectrum. Magnetic Resonance in Chemistry, 43, 736-746. http://dx.doi.org/10.1002/mrc.1609

[42] Zou, J.W., Jiang, Y.J., Guo, M., Hu, G.X., Zhang, B., Liu, H.C. and Yu, Q.S. (2005) Ab Initio Study of the Complexes of Halogen-Containing Molecules RX (X=Cl, Br, and I) and NH3: Towards Understanding the Nature of Halogen Bonding and the Electron-Accepting Propensities of Covalently Bonded Halogen Atoms. Chemistry-A European Journal, 11, 740-751. http://dx.doi.org/10.1002/chem.200400504

[43] Dhami, K.S. and Stothers, J.B. (1965) ${ }^{13}$ C N.M.R. Studies Part III. Carbon-13 N.M.R. Spectra of Substituted Acetophenones. Indian Journal of Chemistry, 43, 479-497.

[44] Bakke, J.M. and Ranes, E. (1997) Nitration of Pyridine by Dinitrogen Pentoxide, a Study of the Reaction Mechanism. Journal of the Chemical Society, Perkin Transactions, 2, 1919-1923. http://dx.doi.org/10.1039/a703079g

[45] Salama, A.T. and Elmorsy, S.S. (2011) Silicon Mediated Synthesis and Selected Transformations of $\beta$-Chloroketones. Chinese Chemical Letters, 22, 1171-1174. http://dx.doi.org/10.1016/j.cclet.2011.05.007

[46] Salama, A.T., Elmorsy, S.S., Khalil, M.A. and Ismail A.M. (2007) A SiCl $\mathrm{ZnCl}_{2}$ Induced General, Mild and Efficient One-Pot, Three-Component Synthesis of $\beta$-Amido Ketone Libraries. Tetrahedron Letters, 48, 6199-6203. http://dx.doi.org/10.1016/j.tetlet.2007.06.128

[47] Salama, A.T., Ismail, A.M., Khalil, M.A. and Elmorsy, S.S. (2012) Silicon-Assisted O-Heterocyclic Synthesis: Mild and Efficient One-Pot Syntheses of (E)-3-Benzylideneflavanones, Coumarin-3-Carbonitriles/Carboxamides, and Benzannulated Spiropyran Derivatives. Archive for Organic Chemistry, 2012, 242-253.

http://dx.doi.org/10.3998/ark.5550190.0013.921 